\title{
Multi-walled carbon nanotubes formed after forest fires improve germination and development of Eysenhardtia polystachya
}

\author{
Gladys Juárez-Cisneros ${ }^{1}$, Mariela Gómez-Romero ${ }^{2}$, Homero Reyes de la Cruz ${ }^{1}$, Jesús Campos-García ${ }^{1}$, Javier \\ Villegas ${ }^{\text {Corresp. } 1}$ \\ ${ }^{1}$ Instituto de Investigaciones Químico Biológicas, Universidad Michoacana de San Nicolás de Hidalgo, Morelia, Michoacán, México \\ 2 Facultad de Biología, Universidad Michoacana de San Nicolás de Hidalgo, Morelia, Michoacán, México \\ Corresponding Author: Javier Villegas \\ Email address: vmoreno@umich.mx
}

Background. Multi-walled carbon nanotubes (MWCNTs) are nanoparticles with countless applications. MWCNTs are typically of synthetic origin. However, recently, the formation of MWCNTs in nature after forest fires has been documented. Previous reports have demonstrated the positive effects of synthetic MWCNTs on the germination and development of species of agronomic interest; nevertheless, there is practically no information on how synthetic or natural MWCNTs affect forest plant development. In this report, based on insights from dose-response assays, we elucidate the comparative effects of synthetic MWCNTs, amorphous carbon, and natural MWCNTs obtained after a forest fire on Eysenhardtia polystachya plant.

Methods. E. polystachya seeds were sown in peat moss-agrolite substrate and conserved in a shade house. Germination was recorded daily up to 17 days after sowing, and plant development (manifested in shoot and root length, stem diameter, foliar area, and root architecture parameters) was recorded 60 days after sowing.

Results. The treatments with natural MWCNTs accelerated the emergence and improved the germination of this plant, thus while no treated seeds achieve $100 \%$ of germination within $16^{\text {th }}$ day, seeds supplemented with natural MWCNTs at doses of $20 \mu \mathrm{g} / \mathrm{mL}$ achieve the above percentage within the $4^{\text {th }}$ day. Natural MWCNTs also promoted fresh and dry biomass in all applied treatments, specially at doses of $40 \mu \mathrm{g} / \mathrm{mL}$ where natural MWCNTs significantly promoted leaf number, root growth, and the dry and fresh weights of shoots and roots of seedlings. Seeds supplemented with doses between 20 and 40 $\mu \mathrm{g} / \mathrm{mL}$ of amorphous carbon achieving $100 \%$ of germination within the $6^{\text {th }}$ day; however, seeds supplemented either with doses of $60 \mu \mathrm{g} / \mathrm{mL}$ of the above carbon or with synthetic MWCNTs at all the tested concentrations could achieve at most $80 \%$ and $70 \%$ of germination respectively within the 17 days. Finally, neither treatments added with amorphous carbon nor those added with synthetic MWCNTs, showed significant increases in the fresh and dry biomass of the tested plant. Likewise, the survival of seedlings was reduced between 10- $20 \%$ with 40 and $60 \mu \mathrm{g} / \mathrm{mL}$ of amorphous carbon, and with synthetic MWCNTs in all the doses applied was reduced at $30 \%$ of survival plants.

Conclusions. These findings indicate that MWCNTs produced by wildfire act as plant growth promoters, contributing to the germination and development of adapted to fire-prone conditions species such as $E$. polystachya. 


\section{Multi-walled carbon nanotubes produced after forest}

2 fires improve germination and development of

3 Eysenhardtia polystachya

4

5

6

7

8

Gladys Juárez-Cisneros ${ }^{1}$, Mariela Gómez-Romero ${ }^{2}$, Homero Reyes-de la Cruz ${ }^{1}$, Jesús CamposGarcía $^{1}$, Javier Villegas ${ }^{1}$

${ }^{1}$ Instituto de Investigaciones Químico Biológicas, Universidad Michoacana de San Nicolás de Hidalgo, Morelia, Michoacán/ México

${ }^{2}$ Cátedras CONACYT-Facultad de Biología, Universidad Michoacana de San Nicolás de Hidalgo, Morelia, Michoacán/ México

Corresponding Author: Javier Villegas ${ }^{1}$

Email address: vmoreno@umich.mx

\section{Abstract}

Background. Multi-walled carbon nanotubes (MWCNTs) are nanoparticles with countless applications. MWCNTs are typically of synthetic origin. However, recently, the formation of MWCNTs in nature after forest fires has been documented. Previous reports have demonstrated the positive effects of synthetic MWCNTs on the germination and development of species of agronomic interest; nevertheless, there is practically no information on how synthetic or natural MWCNTs affect forest plant development. In this report, based on insights from dose-response assays, we elucidate the comparative effects of synthetic MWCNTs, amorphous carbon, and natural MWCNTs obtained after a forest fire on Eysenhardtia polystachya plant.

Methods. E. polystachya seeds were sown in peat moss-agrolite substrate and conserved in a shade house. Germination was recorded daily up to 17 days after sowing, and plant development (manifested in shoot and root length, stem diameter, foliar area, and root architecture parameters) was recorded 60 days after sowing. Results. The treatments with natural MWCNTs accelerated the emergence and improved the germination of this plant, thus while no treated seeds achieve $100 \%$ of germination within $16^{\text {th }}$ day, seeds supplemented with natural MWCNTs at doses of $20 \mu \mathrm{g} / \mathrm{mL}$ achieve the above percentage within the $4^{\text {th }}$ day. Natural MWCNTs also promoted fresh and dry biomass in all applied treatments, specially at doses of $40 \mu \mathrm{g} / \mathrm{mL}$ where natural MWCNTs significantly promoted leaf number, root growth, and the dry and fresh weights of shoots and roots of seedlings. Seeds supplemented with doses between 20 and $40 \mu \mathrm{g} / \mathrm{mL}$ of amorphous carbon achieving $100 \%$ of germination within the $6^{\text {th }}$ day; however, seeds supplemented either with doses of $60 \mu \mathrm{g} / \mathrm{mL}$ of the above carbon or with synthetic MWCNTs at all the tested concentrations could achieve at most $80 \%$ and $70 \%$ of germination respectively within the 17 days. Finally, neither treatments added with amorphous carbon nor those added with synthetic 
41

42

43

44

45

46

47

48

49

50

51

52

53

54

55

56

57

58

59

60

61

62

63

64

65

66

67

68

69

70

71

72

73

74

75

76

77

78

79

80

MWCNTs, showed significant increases in the fresh and dry biomass of the tested plant.

Likewise, the survival of seedlings was reduced between 10- $20 \%$ with 40 and $60 \mu \mathrm{g} / \mathrm{mL}$ of amorphous carbon, and with synthetic MWCNTs in all the doses applied was reduced at $30 \%$ of survival plants.

Conclusions. These findings indicate that MWCNTs produced by wildfire act as plant growth promoters, contributing to the germination and development of adapted to fireprone conditions species such as E. polystachya.

Keywords: nanomaterials; natural multi-walled carbon nanotubes; amorphous carbon; plant growth; forest fires.

\section{Introduction}

Multi-walled carbon nanotubes (MWCNTs) are nanoparticles with unique physicochemical properties that have recently been the focus of scientific, commercial, and biotechnological interest (De Volder et al., 2013; Zhu et al., 2013). In the last two decades, the applications of MWCNTs in different plant species of agronomic interest have been explored. The results documented so far show that MWCNTs promote plant growth. The capacity of MWCNTs to promote early emergence of seeds and increase the percentage of germination has been demonstrated in corn (Tiwari et al., 2014), soybean, barley, and corn hybrids (Lahiani et al., 2013). It has also been reported that synthetic MWCNTs promote elongation and root branching in Brassica oleracea, Daucus carota, Cucumis sativus, Allium sp. (Cañas et al., 2008), and Cicer arietinum (Tripathi, Sonkar \& Sarkar, 2011). However, the phytotoxic effects of MWCNTs have also been reported in several plant species (Vithanage et al., 2017). For example, in lettuce (Lactuca sativa L.) (Ikhtiari et al., 2013), MWCNTs inhibited germination, and limited growth and biomass by inducing cell death. Similarly, in tomato and spinach, single-walled carbon nanotubes (SWCNTs) were shown to inhibit radical elongation (Cañas et al., 2008), while in Cucurbita pepo L., exposure to MWCNTs significantly decreased the germination percentage, root and shoot length, and biomass accumulation (Hatami, 2017). Contrasting effects of these nanoparticles have been associated with intrinsic characteristics, such as their shape, dimensions, electrical conductivity, stability, and limited solubility (Scown, Van Aerle \& Tyler, 2010), as well as the concentration of nanoparticles and the plant species used as the test model (Jackson et al., 2013). To date, MWCNTs have been considered to be synthetic nanoparticles (Liu et al., 2014), obtained principally by arc-discharge, laser ablation, and chemical vapor deposition methods (Zaytseva \& Neumann, 2016). However, Lara-Romero et al. (2017) demonstrated the presence of MWCNTs with 10 layers of graphene in the calcined wood of resinous pine species after forest fire events. Furthermore, the authors performed a thermogravimetric analysis (TGA) to determinate the amount of MWCNTs in the burned wood. The analysis revealed that the wood samples of Pinus oocarpa contained $\sim 2.8 \%$ (w/w) of these nanomaterials. These findings raise questions about the eco-physiological impacts of natural MWCNTs on the plant populations of these ecosystems. There is practically no information about the effects of MWCNTs on 
81 indigenous plant populations; nevertheless, these nanoparticles may play a significant role in the 82 growth and development of such plant species.

83 Eysenhardtia polystachya is a leguminous shrub, characteristic of pine forests in Mexico

84 subjected to fire disturbance. Owing to it is rapid growth and abundant seed production, it is an

85 interesting candidate to test the effects of MWCNTs. The objective of this study was to evaluate 86 and compare the effects of amorphous carbon and MWCNTs of natural and synthetic origin on 87 the germination and morphological seedling variables of E. polystachya.

88

89

90

\section{Materials \& Methods}

\section{MWCNTs and amorphous carbon specifications}

Synthetic MWCNTs used in this study had an outer diameter of 6-13 nm, the internal diameter of $2.0-4.0 \mathrm{~nm}$, length of $2.5-20 \mu \mathrm{m}$, an average wall thickness of 7-13 graphene layers, and purity $>98 \%$ (Aldrich).

Natural MWCNTs were obtained from carbonized P. oocarpa wood samples collected six weeks after a forest fire in Huashan mountain in Nahuatzen Michoacán, Mexico, as described by (LaraRomero et al., 2017). The samples were first sieved using a 0.2-micron mesh to homogenize the particle size, and then calcined at $620^{\circ} \mathrm{C}$ for three hours to mineralize up to $98 \%$ of organic matter from amorphous sources (amorphous carbon).

Non-crystalline carbon samples from Pinus montezumae (rich in amorphous carbon) were also collected from the same site and at the same time, as mentioned previously.

Nanomaterial solutions were prepared by adding natural MWCNTs, synthetic MWCNTs, and amorphous carbon individually to sterile distilled water. For each nanomaterial, solutions with three different concentrations: 20,40 , and $60 \mu \mathrm{g} / \mathrm{mL}$ were prepared. These solutions were sonicated to facilitate the carbon material dispersion, $60 \mathrm{~min}$ before the seed treatments. The above concentrations were chosen in the range of $10-50 \mu \mathrm{g} / \mathrm{mL}$, based on previous studies LaraRomero (2017), that used synthetic MWCNTs (with structural features similar to those found in the natural samples) to evaluate growth and development E. polystachya.

\section{Seed germination and plant growth.}

Seeds of E. polystachya were collected from Cerro del Punhuato, Michoacán, Mexico. Seeds were disinfected with $10 \%(\mathrm{v} / \mathrm{v}) \mathrm{H}_{2} \mathrm{O}_{2}$ for 20 min in Brandson 5510 sonicator. Subsequently, each seed was planted in a polypropylene container with peat moss (PREMIER ${ }^{\circledR}$ )-agrolite substrate (1:2) that had been previously sterilized (Gómez-Romero et al., 2013). $1.0 \mathrm{~mL}$ of the suspension containing the carbon materials at the prepared concentrations were then added to the seeds. The experiments were performed using a completely randomized experimental design. Treatments consisted in: I) natural MWCNTs, II) synthetic MWCNTs, and III) amorphous carbon, each with three different levels (concentration: 20, 40,60 $\mu \mathrm{g} / \mathrm{mL}$ ), replicated eight times in polypropylene containers each with one seed. Treatments were compared with the control (concentration: $0 \mu \mathrm{g} / \mathrm{mL}$ ) with the same number of seeded polypropylene container replicates. 
120 The seeded containers were then placed in a shade house, and watered three times a week,

121 maintaining field capacity during the experiment.

122 Treatments were evaluated at 18 different time intervals; germination was recorded daily up to

12317 days after sowing, and plant development was recorded at the end of the trial, i.e., 60 days

124 after sowing.

125 To record its development, plants were removed from the containers, and the roots were washed

126 with running water to remove the adhering substrate residues. The percentage of survival was

127 registered, after which the plants were cut from the base of the stem, and shoot and root length,

128 stem diameter, and foliar area were measured. Variables of root architecture, such as primary

129 root length, lateral roots, tertiary roots, and root volume, were also recorded using the

130 WinRHIZO software coupled to an EPSON Expression 11000XL scanner (Régent Instruments

131 Inc., Québec, CA). Finally, the shoot and the root were weighed separately, then placed in paper

132 bags and allowed to dry at room temperature before being weighed again to obtain the dry

133 weight.

134

135 Statistical analysis

136 Germination cumulated data, available for 17 days, were analyzed using a generalized linear

137 model (GLM) with a binomial distribution and Cox analysis, to determine the behavior of the 138 germination curves between treatments over time.

139 Growth data were analyzed using one-way ANOVA, and the means were compared using

140 Tukey's tests with $P<0.05$, in GraphPad software. The analyses were performed using eight

141 repetitions to balance out the effect of non-germinated seeds.

142

143 Results

144 Seed germination and survival of $E$. polystachya

145 Natural MWCNTs accelerated the germination of this legume; at the end of the germination test,

146 Cox's proportional hazards test indicated that the germination rates during the test period were

147 significantly different $\left(X^{2}=17.04, P=0.01\right)$. E. polystachya seeds exposed to different carbon

148 sources showed different germination rates. Three days after sowing, $60-90 \%$ germination was

149 recorded in seeds treated with natural MWCNTs compared with 40\% those kept as control.

150 While six days after sowing, seeds treated with natural MWCNTs had reached 100\%

151 germination in all the doses applied, compared with $90 \%$ of germination in control, an $80 \%-$

$152100 \%$ germination in seeds treated with amorphous carbon and 70-80 with synthetic MWCNTs

153 (Table 1). Furthermore, the control seeds took 16 days to reach 100\% germination, and it was

154 evident that synthetic MWCNTs slowed down seed germination, which reached a maximum of

$15590 \%$ in the same period.

156 E. polystachya plant observed sixty days after sowing (Table 1), showed $100 \%$ survival in the

157 control group and groups treated with natural MWCNTs (all doses) or $20 \mu \mathrm{g} / \mathrm{mL}$ of amorphous

158 carbon. In contrast, seeds treated with 40 and $60 \mu \mathrm{g} / \mathrm{mL}$ of amorphous carbon showed $90 \%$ and

$15980 \%$ survival, respectively, indicating that an increase in amorphous carbon concentration

Peer] reviewing PDF | (2019:09:41130:1:1:NEW 15 Jan 2020) 
160

161

162

163

164

165

166

167

168

169

170

171

172

173

174

175

176

177

178

179

180

181

182

183

184

185

186

187

188

189

190

191

192

193

194

195

196

197

198

199

resulted in a decreased survival percentage. The addition of synthetic MWCNTs also negatively affected E. polystachya survival. We obtained $70 \%$ survival with all the doses applied of synthetic MWCNTs.

\section{Aerial growth of $E$. polystachya}

The effects of natural MWCNTs, amorphous carbon, and synthetic MWCNTs at concentrations of $0,20,40$, and $60 \mu \mathrm{g} / \mathrm{mL}$ on the seeds of E. polystachya grown in shade house conditions sixty days after sowing are shown in the figures 1,2 . We observed that treatment with $40 \mu \mathrm{g} / \mathrm{mL}$ of natural MWCNTs significantly promoted leaf formation, when compared with treatment with synthetic MWCNTs and control (Fig 2a), but no significant difference was observed in other treatments (Tukey test with $P<0.05$ ). Furthermore, treatments containing natural MWCNTs significantly increased the foliar area at all concentrations tested, while amorphous carbon and synthetic MWCNTs did not have any significant effect (Fig $2 b$ ). In addition, no significant differences were observed in the height of E. polystachya plants treated with natural MWCNTs or amorphous carbon and those kept as controls (Fig 2c) according with Tukey test $(P<0.05)$. However, treatments with synthetic MWCNTs negatively affected plant height at concentrations of $60 \mu \mathrm{g} / \mathrm{mL}$. The aerial dry weight of plants treated with $40 \mu \mathrm{g} / \mathrm{mL}$ of natural MWCNTs was significantly higher, while plants under other treatments did not show any difference with respect to the control (Fig 2d).

\section{Root architecture of $E$. polystachya}

The effects of natural and synthetic MWCNTs and amorphous carbon on root architecture of $E$. polystachya were evaluated 60 days after sowing (Fig 3). It was observed that the primary root length showed significant increases in treatments with natural MWCNTs, compared to the control plants (Fig 4a); however, the number of secondary roots did not show significant differences between the treatments containing the tested materials and the control (Fig 4c). It was evident that treatments with 40 and $60 \mu \mathrm{g} / \mathrm{mL}$ of natural MWCNTs modified the root architecture by promoting the formation of tertiary roots (Fig $4 \mathrm{~b}$ ), significantly increases in the root volume were observed in plants treated with 40 and $60 \mu \mathrm{g} / \mathrm{mL}$ of natural MWCNTs compared to the control group and treatments containing synthetic MWCNTs or amorphous carbon (Fig 4d) according to with Tukey test $(P<0.05)$.

Furthermore, the fresh and dry root weights of E. polystachya seeds treated with natural MWCNTs at concentrations higher than $40 \mu \mathrm{g} / \mathrm{mL}$ were significantly increased (Figs $4 \mathrm{e}, 4 \mathrm{f}$ ) compared to the weights recorded in other treatments. Conversely, the addition of amorphous carbon and synthetic MWCNTs significantly decreased the dry root weight at concentrations above 20 and $40 \mu \mathrm{g} / \mathrm{mL}$ according to with Tukey test $(P<0.05)$.

\section{Discussion}

The use of synthetic MWCNTs as plant growth promoters has been reported in several crop plants in the two last decades (Khodakovskaya et al., 2012, 2013; Lahiani et al., 2015). The 
200

201

202

203

204

205

206

207

208

209

210

211

212

213

214

215

216

217

218

219

220

221

222

223

224

225

226

227

228

229

230

231

232

233

234

235

236

237

238

239

scientific findings report both positive (Joshi et al., 2018a,b) and negative (Ikhtiari et al., 2013; McGehee et al., 2017) effects of synthetic MWCNTs on plants species. However, to date, the effects of naturally occurring MWCNTs are poorly known. Thus, in the present study, we evaluated the effects of natural and synthetic MWCNTs as well as amorphous carbon on the germination and development of E. polystachya plants grown in shade house conditions. The responses of this legume to the MWCNTs treatments were contrasting, depending on the origin of the nanomaterial, i.e., MWCNTs of natural origin collected from forest fires events promoted early emergence and increased the germination percentage of the seeds, while synthetic MWCNTs negatively affected seed germination (Table 1). It has been previously reported that the effects of MWCNTs in plants and other organisms depend on their physicochemical properties, such as surface area, length, and diameter, the presence of functional groups, load, shape, and solubility.

In this study, the MWCNTs formed naturally after forest fires lead to better tested plant growth and development than MWCNTs obtained from chemical synthesis. It has been shown that MWCNTs with different characteristics affect seed germination. Early germination induced by synthetic MWCNTs has been reported in tomato seeds, soybean, barley, corn (Lahiani et al., 2013), oat (Joshi et al., 2018b), wheat (Wang et al., 2012; Joshi et al., 2018a), and Lupinus elegans (Lara-Romero et al., 2017). Increased seed germination has been associated with increased water uptake during seed imbibition, facilitated by the formation of new pores during penetration of seed coat and cell walls by the MWCNTs; however, the action mechanism of these structures on seed germination is not completely clear. In that context, it has been documented that several chemical and physical factors can influence the biochemical and physiological events that control the germination in seeds (Nelson et al., 2012; Asghar et al., 2017).

The effect of MWCNTs has also been documented in other physiological stages of plant development. It has been suggested that a plant response to these nanomaterials depends on their intrinsic chemical characteristics, concentration (Lahiani et al., 2013; Lara-Romero et al., 2017), dispersion method (Joshi et al., 2018a,b), and also on the plant species (Zhai et al., 2015; Zaytseva, 2016) and the experimental conditions in which it develops (Tiwari et al., 2014). Thus, the effects of MWCNTs can be positive, as observed in the E. polystachya plants cultivated with $40 \mu \mathrm{g} / \mathrm{mL}$ of natural MWCNTs, where the plants showed greater vegetative area, more abundant foliage, and more aerial area. Our results evidenced that natural MWCNTs modified the root architecture of this legume, as a higher number of tertiary roots and higher root volume were observed, which is beneficial for its establishment, allowing for greater gaseous exchange and absorption of water and minerals (Lynch, 1995). In addition, plants treated with natural MWCNTs showed a significant increase in dry weights of both shoot and root. Similar effects have been documented for synthetic MWCNTs in oat (Joshi et al., 2018b), wheat (Joshi et al., 2018a), corn (Tiwari et al., 2014; Zhai et al., 2015), and Lupinus elegans (Lara-Romero et al., 2017). However, the mechanisms by which MWCNTs promote plant growth and development are not clear. Some reports suggest that MWCNTs activate mechanisms of cell division 
240 (Khodakovskaya et al., 2012) and promote elongation of xylem and phloem cells, which

241 consequently influence the uptake of water and nutrients (Joshi et al., 2018a,b).

242 It must be noted that toxic effects of synthetic MWCNTs on species of agronomic interest have

243 also been previously reported, such as in Lactuca sativa (Ikhtiari et al., 2013), Amaranthus

244 tricolor L., and Cucumis sativus (Begum, Ikhtiari \& Fugetsu, 2014). In this study, we found that

245 synthetic MWCNTs, at the concentrations tested, negatively affected the physiological

246 development of $E$. polystachya, by altering germination, morphometric variables aerial plant

247 parts, and root architecture. The mechanisms associated with MWCNT toxicity have not been

248 elucidated in detail; however, they are associated with cell death in roots and leaves, caused by

249 an increase in the generation of reactive oxygen species (Ikhtiari et al., 2013) and rupture of cell

250 membranes (Begum, Ikhtiari \& Fugetsu, 2014).

251

252

\section{Conclusions}

253

254

255

256

257

258

259

260

261

262

263

264

265

266

267

268

269

270

271

272

273

274

275

276

277

278

279

280

281

282

In this work, for the first time, we report the effects of natural MWCNTs collected from burned trees after a forest fire. We observed that these MWCNTs improved and accelerated germination in E. polystachya seeds and promoted growth, in both aerial and underground parts. We also observed that amorphous carbon did not significantly affect the development of this plant. In contrast, MWCNTs from synthetic origins were observed to negatively affect plant development. These results suggest that natural nanoparticles produced after forest fires may positively affect the growth and development of plants in these ecosystems.

Asghar T, Iqbal M, Jamil Y, Zia ul H, Nisar J, Shahid M. 2017 Comparison of He-Ne LASER and sinusoidal non-uniform magnetic field seed pre-sowing treatment effect on Glycine max (Var 90-I) germination, growth and yield, Journal of Photochemistry and Photobiology B: Biology. 166:212-219. DOI: 10.1016/j.jphotobiol.2016.11.018

Begum P, Ikhtiari R, Fugetsu B. 2014. Potential Impact of Multi-Walled Carbon Nanotubes Exposure to the Seedling Stage of Selected Plant Species. Nanomaterials 4:203-221. DOI: 10.3390/nano4020203.

Cañas JE, Long M, Nations S, Vadan R, Dai L, Luo M, Ambikapathi R, Lee EH, Olszyk D. 2008. Effects of functionalized and nonfunctionalized single-walled carbon nanotubes on root elongation of select crop species. Environmental Toxicology and Chemistry 27:19221931. DOI: 10.1897/08-117.1.

Gómez-Romero M, Villegas J, Sáenz-Romero C, Lindig-Cisneros R. 2013. Efecto de la micorrización en el establecimiento de Pinus pseudostrobus en cárcavas. Madera Bosques 19:51-63.

Hatami M. 2017. Toxicity assessment of multi-walled carbon nanotubes on Cucurbita pepo L. under well-watered and water-stressed conditions. Ecotoxicology and Environmental Safety 142:274-283. DOI: 10.1016/j.ecoenv.2017.04.018.

Ikhtiari R, Begum P, Watari F, Fugetsu B. 2013. Toxic Effect of Multiwalled Carbon Nanotubes on Lettuce ( Lactuca Sativa ). 5:18-24.

Jackson P, Jacobsen NR, Baun A, Birkedal R, Kühnel D, Jensen KA, Vogel U, Wallin H. 2013. Bioaccumulation and ecotoxicity of carbon nanotubes. Chemistry Central Journal 7:1-21. DOI: $10.1186 / 1752-153 X-7-154$. 
283

284

285

286

287

288

289

290

291

292

293

294

295

296

297

298

299

300

301

302

303

304

305

306

307

308

309

310

311

312

313

314

315

316

317

318

319

320

321

322

323

324

325

326

327

328

Joshi A, Kaur S, Dharamvir K, Nayyar H, Verma G. 2018a. Multi-walled carbon nanotubes applied through seed-priming influence early germination, root hair, growth and yield of bread wheat (Triticum aestivum L.). Journal of the Science of Food and Agriculture 98. DOI: $10.1002 /$ jsfa. 8818 .

Joshi A, Kaur S, Singh P, Dharamvir K, Nayyar H, Verma G. 2018b. Tracking multi-walled carbon nanotubes inside oat (Avena sativa L.) plants and assessing their effect on growth, yield, and mammalian (human) cell viability. Applied Nanoscience 0:0. DOI: 10.1007/s13204-018-0801-1.

Khodakovskaya M V, Kim B-S, Kim JN, Alimohammadi M, Dervishi E, Mustafa T, Cernigla CE. 2013. Carbon nanotubes as plant growth regulators: effects on tomato growth, reproductive system, and soil microbial community. Small (Weinheim an der Bergstrasse, Germany) 9:115-23. DOI: 10.1002/smll.201201225.

Khodakovskaya M V., De Silva K, Biris AS, Dervishi E, Villagarcia H. 2012. Carbon nanotubes induce growth enhancement of tobacco cells. ACS Nano 6:2128-2135. DOI: $10.1021 / \mathrm{nn} 204643 \mathrm{~g}$.

Lahiani MH, Chen J, Irin F, Puretzky AA, Green MJ, Khodakovskaya M V. 2015. Interaction of carbon nanohorns with plants: Uptake and biological effects. Carbon 81:607-619. DOI: 10.1016/j.carbon.2014.09.095.

Lahiani MH, Dervishi E, Chen J, Nima Z, Gaume A, Biris AS, Khodakovskaya M V. 2013. Impact of carbon nanotube exposure to seeds of valuable crops. ACS Applied Materials and Interfaces 5:7965-7973. DOI: 10.1021/am402052x.

Lara-Romero J, Campos-García J, Dasgupta-Schubert N, Borjas-García S, Tiwari DK, ParaguayDelgado F, Jiménez-Sandoval S, Alonso-Nuñez G, Gómez-Romero M, Lindig-Cisneros R, De la Cruz HR, Villegas JA. 2017. Biological effects of carbon nanotubes generated in forest wildfire ecosystems rich in resinous trees on native plants. PeerJ 2017:1-15. DOI: 10.7717/peerj.3658.

Liu W-W, Chai S-P, Mohamed AR, Hashim U. 2014. Synthesis and characterization of graphene and carbon nanotubes: A review on the past and recent developments. Journal of Industrial and Engineering Chemistry 20:1171-1185. DOI: 10.1016/j.jiec.2013.08.028.

Lynch J. 1995. Root Architecture and Plant Productivity. Plant Physiology 109:7-13. DOI: 10.1104/pp.109.1.7.

McGehee DL, Lahiani MH, Irin F, Green MJ, Khodakovskaya MV. 2017. Multiwalled Carbon Nanotubes Dramatically Affect the Fruit Metabolome of Exposed Tomato Plants. ACS Applied Materials and Interfaces 9:32430-32435. DOI: 10.1021/acsami.7b10511.

Nelson DC, Flematti GR, Ghisalberti EL, Dixon KW, Smith SM. 2012. Regulation of seed germination and seedling growth by chemical signals from burning vegetation. Annual Review of Plant Biology. 63: 107-130.

Scown TM, Van Aerle R, Tyler CR. 2010. Review: Do engineered nanoparticles pose a significant threat to the aquatic environment. Critical Reviews in Toxicology 40:653-670. DOI: $10.3109 / 10408444.2010 .494174$.

Tiwari DK, Dasgupta-Schubert N, Villaseñor Cendejas LM, Villegas J, Carreto Montoya L, Borjas García SE. 2014. Interfacing carbon nanotubes (CNT) with plants: enhancement of growth, water and ionic nutrient uptake in maize (Zea mays) and implications for nanoagriculture. Applied Nanoscience (Switzerland) 4:577-591. DOI: 10.1007/s13204-0130236-7.

Tripathi S, Sonkar SK, Sarkar S. 2011. Growth stimulation of gram (Cicer arietinum) plant by

Peer) reviewing PDF | (2019:09:41130:1:1:NEW 15 Jan 2020) 
343

344

345

346

347

348

349

350

351

352

353

354

355

356

357

358

359

360

361

362

363

364

365

366

367

368

369

370

371

water soluble carbon nanotubes. Nanoscale 3:1176-1181. DOI: 10.1039/c0nr00722f.

Vithanage M, Seneviratne M, Ahmad M, Sarkar B, Ok YS. 2017. Contrasting effects of engineered carbon nanotubes on plants: a review. Environmental Geochemistry and Health 39:1421-1439. DOI: 10.1007/s10653-017-9957-y.

De Volder MFL, Tawfick SH, Baughman RH, Hart a J. 2013. Carbon nanotubes: present and future commercial applications. Science (New York, N.Y.) 339:535-9. DOI: $10.1126 /$ science. 1222453.

Wang X, Han H, Liu X, Gu X, Chen K, Lu D. 2012. Multi-walled carbon nanotubes can enhance root elongation of wheat (Triticum aestivum) plants. Journal of Nanoparticle Research 14. DOI: $10.1007 / \mathrm{s} 11051-012-0841-5$.

Zaytseva O. 2016. Differential Impact of Multi-Walled Carbon Nanotubes on Germination and Seedling Development of Glycine Max , Phaseolus Vulgaris. European Chemical Bulletin 5:202-210. DOI: 10.17628/ECB.2016.5.202.

Zaytseva O, Neumann G. 2016. Carbon nanomaterials: Production, impact on plant development, agricultural and environmental applications. Chemical and Biological Technologies in Agriculture 3:1-26. DOI: 10.1186/s40538-016-0070-8.

Zhai G, Gutowski SM, Walters KS, Yan B, Schnoor JL. 2015. Charge, Size, and Cellular Selectivity for Multiwall Carbon Nanotubes by Maize and Soybean. Environmental Science and Technology 49:7380-7390. DOI: 10.1021/acs.est.5b01145.

Zhu M, Nie G, Meng H, Xia T, Nel A, Zhao Y. 2013. Physicochemical properties determine nanomaterial cellular uptake, transport, and fate. Accounts of Chemical Research 46:622631. DOI: 10.1021/ar300031y.

\section{Legend figures}

Figure 1

Images showing the effect of synthetic MWCNTs, carbon amorphous and natural MWCNTs on the growth of Eysenhardtia polystachya.

Seeds of $E$. polystachya were planted in containers with peat moss-agrolite substrate and supplemented with $1.0 \mathrm{~mL}$ suspension containing either 0 (control), 20, 40, or 60 $\mu \mathrm{g} / \mathrm{mL}$ of the different carbon materials. Panels $A$ and $B$ correspond to 20 and 60 days after planting, respectively.

Figure 2

Effect of synthetic MWCNTs, amorphous carbon and natural MWCNTs on aerial biometric parameters of Eysenhardtia polystachya plants. 
372 Seeds of E. Polystachya were supplemented with $1.0 \mathrm{~mL}$ suspension containing either 3730 (control), 20,40 , or $60 \mu \mathrm{g} / \mathrm{mL}$ of the different carbon materials. After 60 days of 374 planting, the plants were harvested, and biometric variables were recorded. (a) Leaves 375 number, (b) foliar area, (c) height, (d) aerial dry weight. Bars represent mean \pm SE of 376 three independent assays. $n=8$. One-way analysis of variance (ANOVA) was carried 377 out with Tukey's post hoc test; statistical significance $(P<0.05)$ between treatments with 378 respect to control is indicated with different uppercase letters.

379

380

381

382

383

384

385

386

387

388

389

390

391

392

393

394

395

396

397

398

399

400

Figure 3

Effect of natural MWCNTs, amorphous carbon and synthetic MWCNTs on root development of Eysenhardtia polystachya.

The images show root architecture changes in response to different carbon materials in E. polystachya roots harvested 60 days after planting.

Figure 4

Effect of synthetic MWCNTs, amorphous carbon, and natural MWCNTs on root architecture of Eysenhardtia polystachya plants.

Seeds of E. polystachya were supplemented with $1.0 \mathrm{~mL}$ suspension containing either 0 (control), 20,40 , or $60 \mu \mathrm{g} / \mathrm{mL}$ of the different carbon materials. After 60 days of planting, the plants were harvested, and root architecture variables were recorded. (a) Primary root length, (b) Lateral roots number, (c) tertiary roots number, (d) Root volume, (e) Root fresh weight, and (f) Root dry weight. Bars represent mean \pm SE of three independent assays. $n=8$. One-way analysis of variance (ANOVA) was carried out with Tukey's post hoc test; statistical significance $(P<0.05)$ between treatments with respect to control is indicated with different uppercase letters.

401

402

403

404

405

406 


\section{Table $\mathbf{1}$ (on next page)}

Effect of synthetic MWCNTs, carbon amorphous and natural MWCNTs on Germination and survival of Eysenhardtia polystachya.

Seeds of E.polystachya were supplemented with $1.0 \mathrm{~mL}$ suspension containing either 0 (control), 20,40, or $60 \mu \mathrm{g} / \mathrm{mL}$ of the different carbon materials. Germination was recorded daily up to 17 days after sowing, and survival was recorded at the end of the trial, 60 days after sowing. The results represent the mean of three independent assays with $n=8$. The germination was analyzed through a generalized linear model (GLM) for the data, with a binomial distribution and a Cox analysis. 
Days after planting

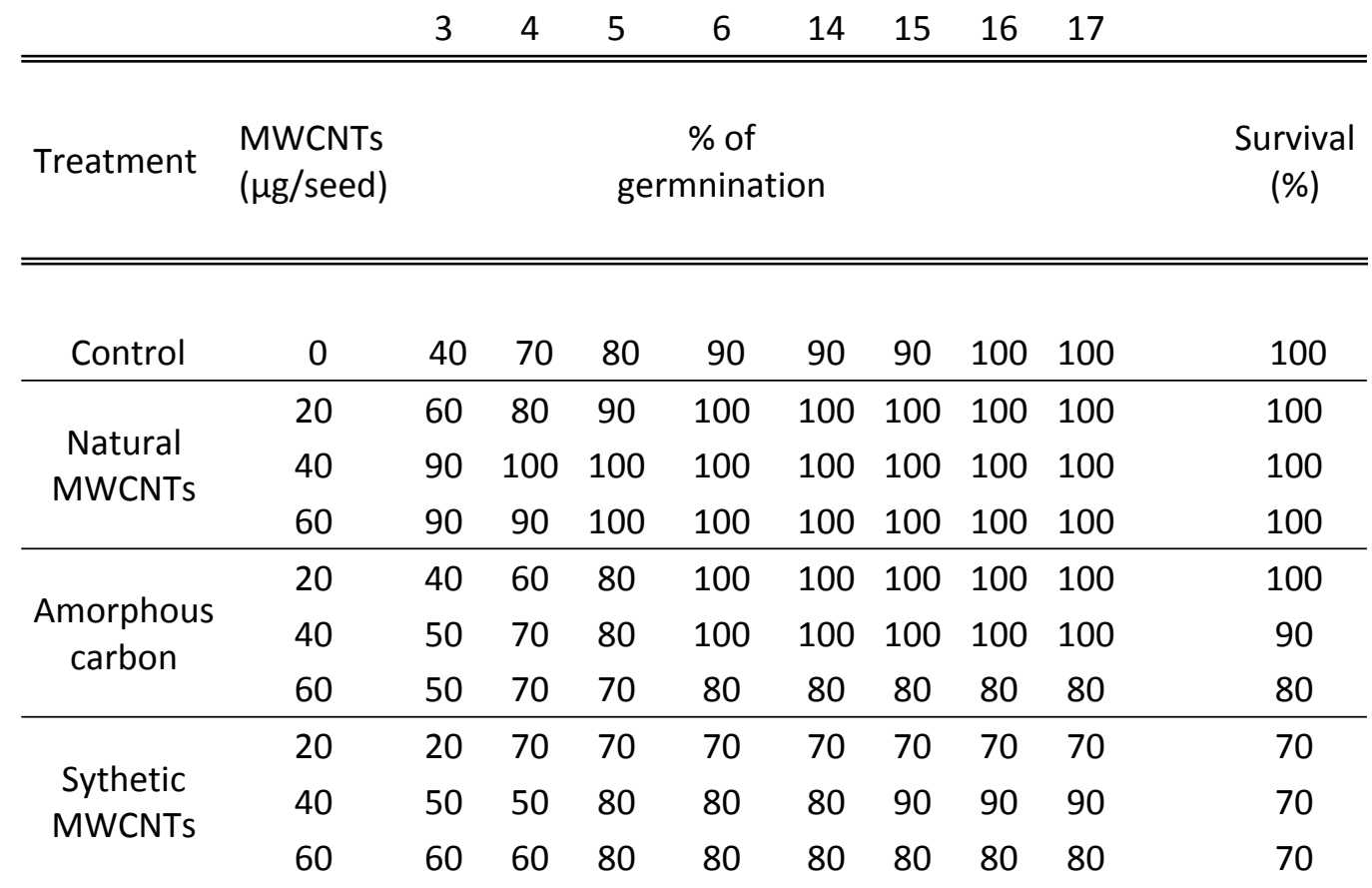

3

4 


\section{Figure 1}

Images showing the effect of synthetic MWCNTs, carbon amorphous and natural MWCNTs on growth of Eysenhardtia polystachya.

Seeds of E. polystachya were planted in containers with peat moss-agrolite substrate and supplemented with $1.0 \mathrm{~mL}$ suspension containing either 0 (control), 20, 40, or $60 \mu \mathrm{g} / \mathrm{mL}$ of the different carbon materials. Panels A and B correspond to 20 and 60 days after planting respectively.

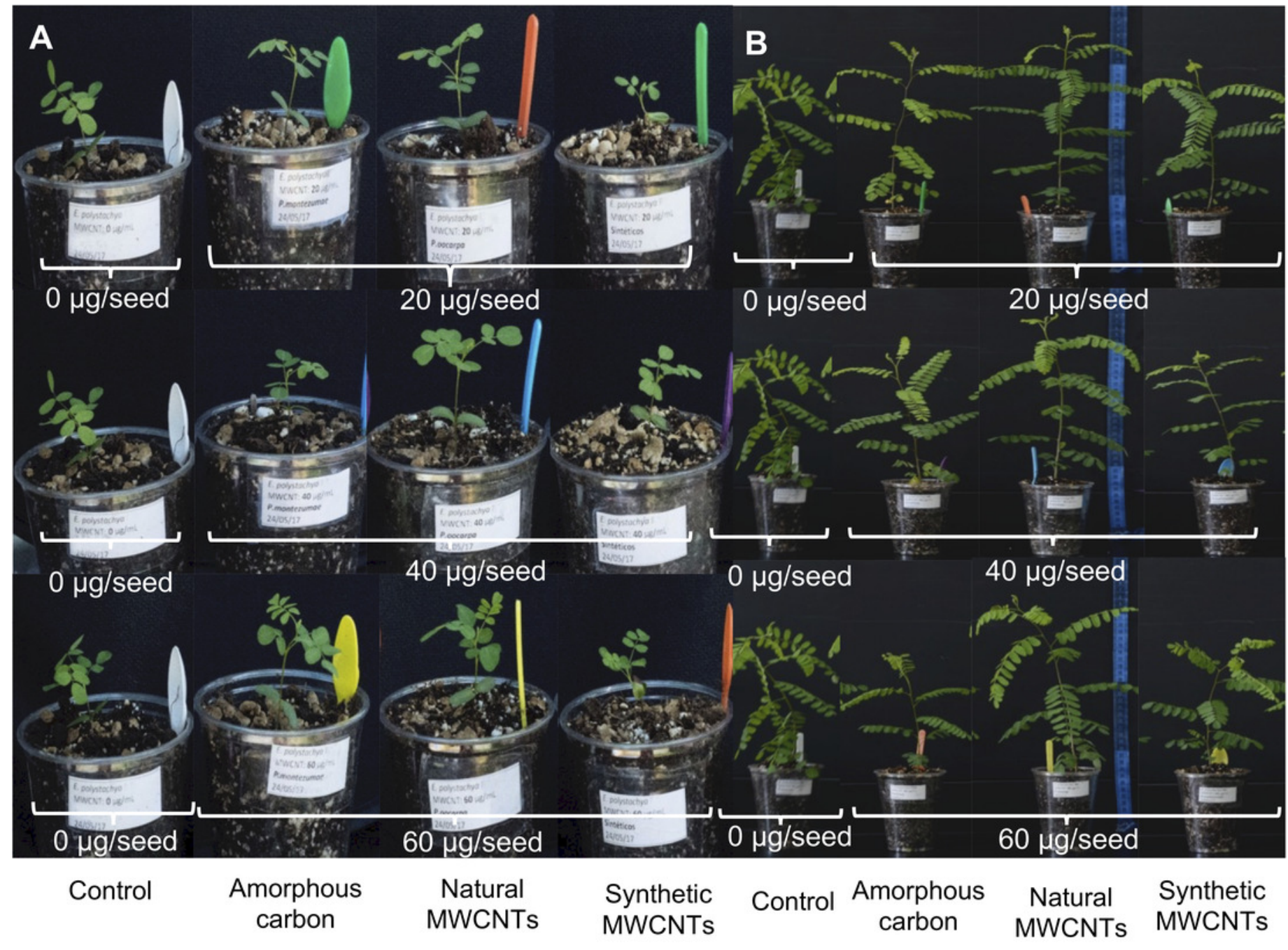




\section{Figure 2}

Effect of synthetic MWCNTs, amorphous carbon and natural MWCNTs on aereal biometric parameters of Eysenhardtia polystachya plants.

Seeds of $E$. polystachyawere supplemented with $1.0 \mathrm{~mL}$ suspension containing either 0 (control), 20,40 , or $60 \mu \mathrm{g} / \mathrm{mL}$ of the different carbon materials. After 60 days of planting the plants were harvested and biometric variables were recorded. (a) Leaves number, (b) foliar area, (c) height, (d) aerial dry weight. Bars represent mean \pm SE of three independent assays. $n=8$. One-way analysis of variance (ANOVA) was carried out with Tukey's post hoc test; statistical significance $(P<0.05)$ between treatments with respect to control is indicated with different lowercase letters. 

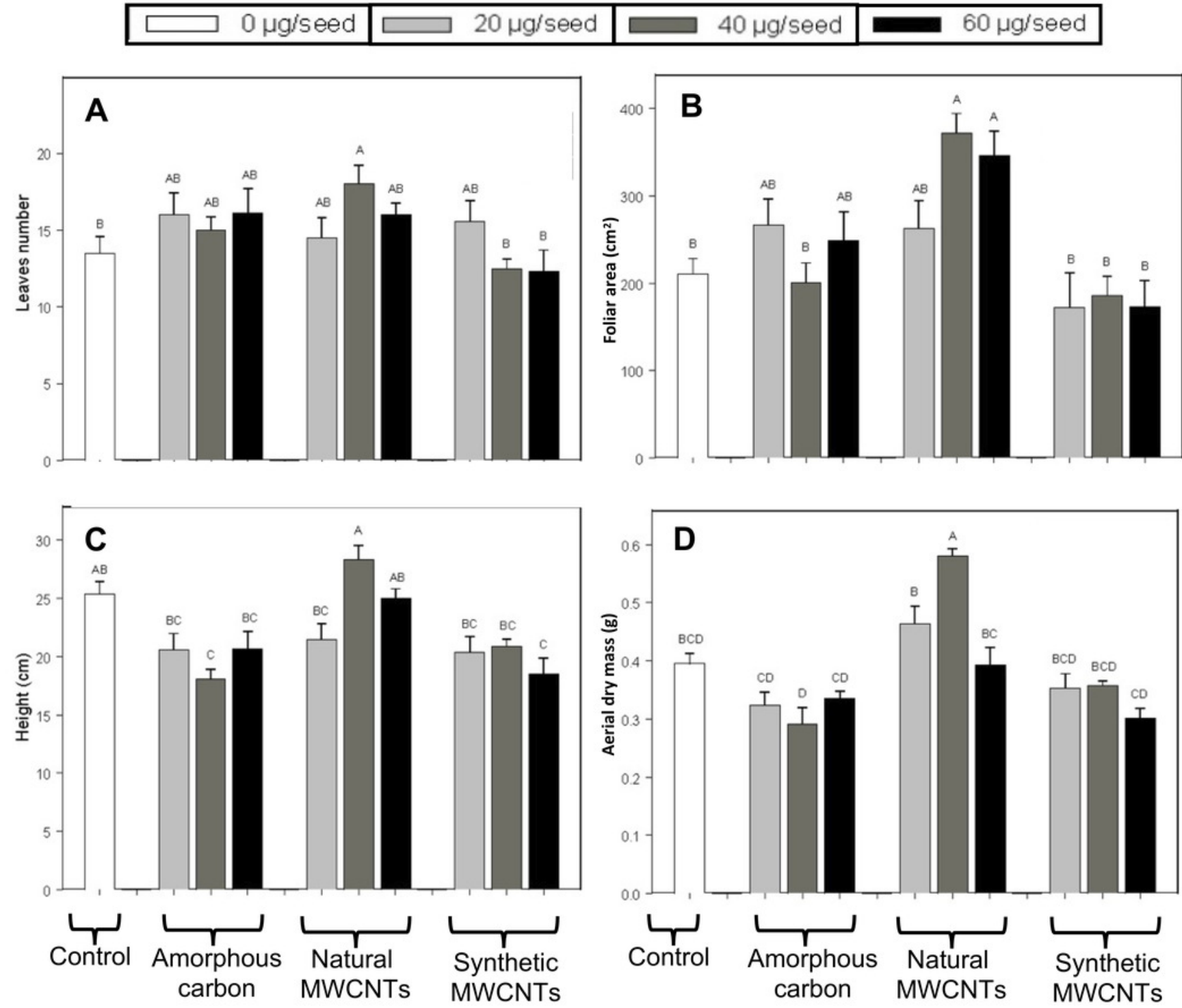
Figure 3

Effect of natural MWCNTs, amorphous carbon and synthetic MWCNTs on root development of Eysenhardtia polystachya.

The images show root architecture changes in response to different carbon materials in $E$. polystachya roots harvested 60 days after planting. 


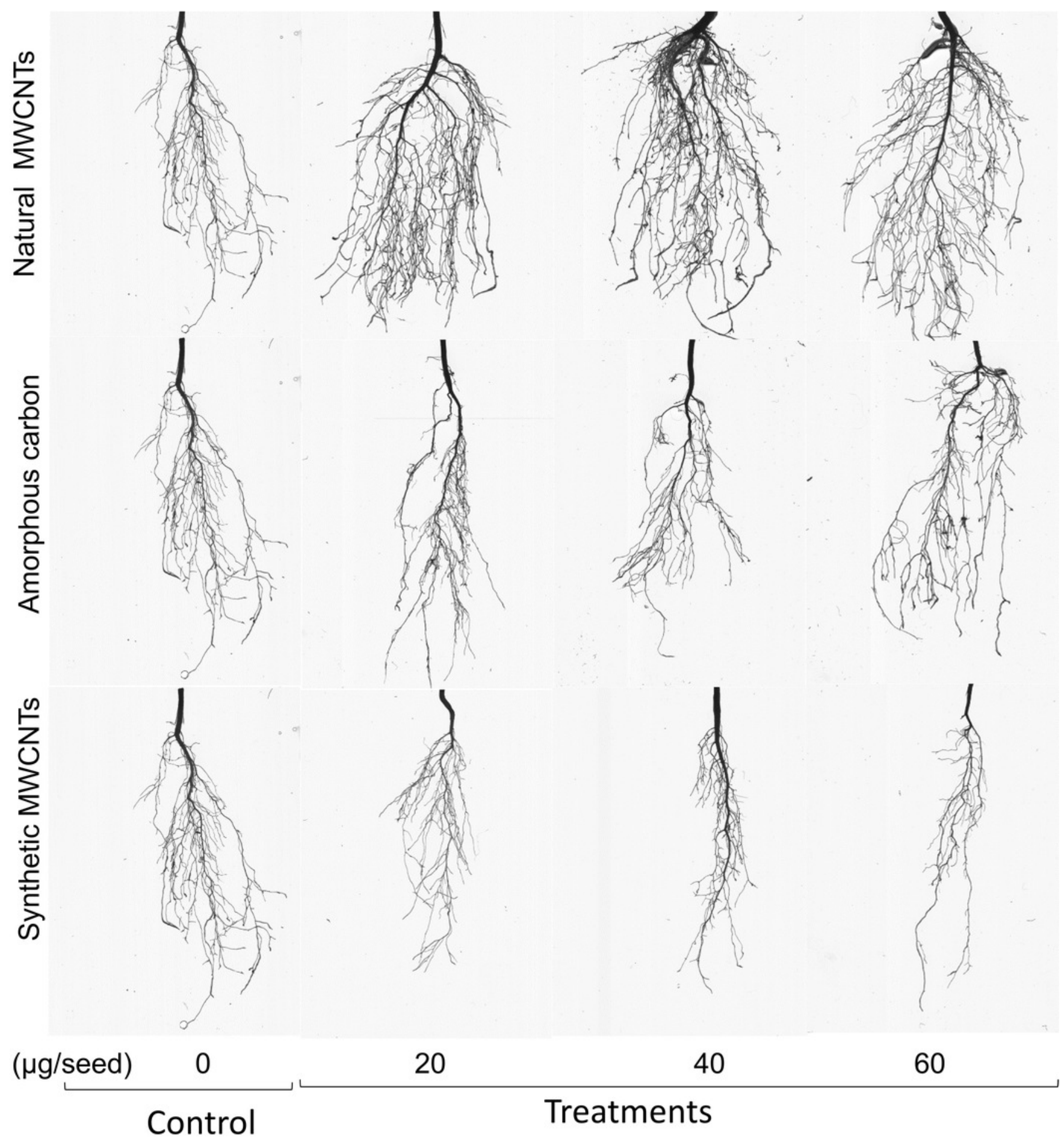




\section{Figure 4}

Effect of synthetic MWCNTs, amorphous carbon and natural MWCNTs on root architecture of Eysenhardtia polystachya plants.

Seeds of $E$. polystachya were supplemented with $1.0 \mathrm{~mL}$ suspension containing either 0 (control), 20, 40, or $60 \mu \mathrm{g} / \mathrm{mL}$ of the different carbon materials. After 60 days of planting the plants were harvested and root architecture variables were recorded.(a) Primary root length, (b) Lateral roots number, (c) tertiary roots number, (d) Root volume, (e) Root fresh weight, and (f) Root dry weight. Bars represent mean \pm SE of three independent assays. $n=8$. Oneway analysis of variance (ANOVA) was carried out with Tukey's post hoc test; statistical significance $(P<0.05)$ between treatments with respect to control is indicated with different lowercase letters. 

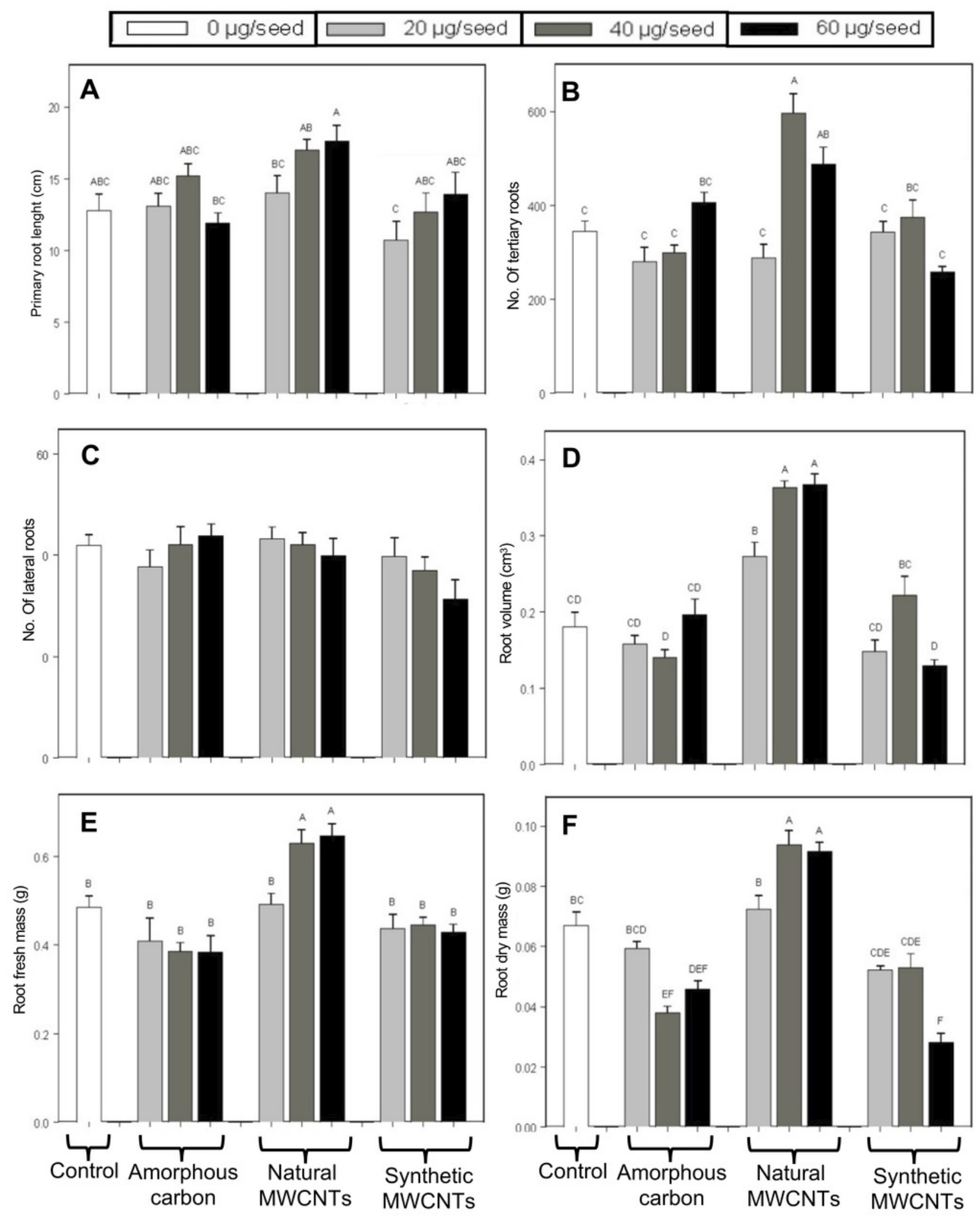